\title{
Research on Service Crisis Management of University Library
}

\author{
Pan Hui ${ }^{\mathrm{a}}$; Ou Ruixiang ${ }^{\mathrm{a}}$; Huang Yao ${ }^{\mathrm{b}}$ \\ a Library, South China University of Technology, Guangzhou, 510640, China \\ b Propaganda Department, Southern Medical University, Guangzhou, 510515, China
}

Key words: service crisis; crisis management; library; library users

Abstract: According to the understanding of the library service crisis management and the field where university library service crisis occur, the library service is divided into three parts: service item, service mode and service quality. By analyzing the current level of university library service, this paper puts forward some measures and suggestions to promote the service and management level on service item, service mode and service quality of university library.

The rapid development and deep application of digital technology has caused great impact on the traditional library service, and also resulted in the various risk factors of the library service which is caused by dealing with the development of the information, but also created favorable environment to improve the library service and management ability. The ever-changing information technologies not only accelerates the development of social economy, makes the library system face increasingly complex internal and external environment, but also objectively increase its crisis elements. Therefore, the crisis identification and prevention management has gradually become the core content of the library service level. The research and analysis of the related problems has also become the focus of the library service theory and practice, and the service crisis theory can be applied to the library to solve the problem which the traditional library service failed to do.

\section{University Library Service Crisis}

The meaning and nature of the crisis in the specific field of university library service mainly manifests the difference between the service and the actual demand of the service object provided by the service body. The service body doing service management will lead a variety of problems, resulting in the failure to provide services, resulting in more serious consequences of the crisis. The service crisis management of university library refers specifically to that the service subject of the university library can deal with the problems and potential risk factors in its service, identify the elements of crisis, make the prevention and control of the crisis, and reduce the crisis as much as possible, so as to ensure the healthy and stable development of the library management.

The service personnel of universities library should be vigilant in order to improve their own service awareness and management level, and actively solve the potential risks and contradictions, try to avoid the occurrence of service crisis and avoid serious harm to them. They must do some optimization strategy to 
implementation efficient library service from the perspective of library service crisis prevention.

\section{The Content of the Library Service Crisis}

\subsection{Service item Crisis}

With the rapid development of society, especially the development of Internet technology, the channels of users' reading are richer than before, the demand of information and service is becoming more and more diversified. The serious crisis of traditional libraries is as follows: books are so old and they are not update in time, that books which receives little attention are in idle, while popular books are still in short supply . In general, there is a significant structural difference between the library's resource supply and user needs. In addition, the library lacks the recommendation and presentation of its own services, which leads to little knowledge of the library's service items, which exacerbates the library's crisis situation.

\subsection{Service mode Crisis}

At present, the university library services generally apply the way which takes the integrated automated information system to provide users with information services. This service is relatively monotonous, failed to keep up with the current trend of technological development, cannot meet the users diversification and intelligent needs.

Compared with the current social and technological development, the management of university library service has the following shortcomings:

(1)Paper literature that traditional information carrier has been difficult to meet the user's needs of multimedia information, books of paper materials are in short.

(2) Lack of positive initiative. At present, the concept of library management in universities still stays in the past literature borrowing level, the management is relatively conservative and cannot interact with the external organization, and the service item is obsolete and restricts the function of the library application. The era of information technology is the era of rapid development of media technology, a large number of emerging media resources continue to emerge, especially in universities which are this country's most powerful creativity, the most cutting-edge areas, students demand for multimedia services is much higher than other areas of society. Especially as the media technology develops, it provides users with a way to express them, but also provides the conditions for the emergence of public opinion crisis. How to prevent and solve the public opinion crisis will also become an important part of university library service management.

\subsection{Service quality Crisis}

Quality of service mainly comes from the library staff's business efficiency and work attitude, is a direct impact on the user's senses and attitudes. AS the main communication with the user, the quality and performance of the staff will be the most important basis that the user evaluates the library service quality. Due to the imperfect mechanism of library management, the backwardness of service and the lack of professionalism, it cannot provide timely and effective service for users, and even cause some damage to users, which lead to the loss of 
users.

3. The Status of University Library Service from the Perspective of Service Crisis

\section{1 service object and mode change, service crisis prevention faces challenges.}

The traditional library service system which make the literature as the core has gradually changed the new service management that make the user as the core .Under the impetus of the development of social information, the object and mode of service have changed significantly, and the service crisis has become an important library crisis beyond traditional natural disasters. The development of information technology has weakened the traditional status of the library's information resources, which has attracted more attention to the users of the library, which has exacerbated the loss of the library users and expanded the service crisis of the library.

With the service innovation of university library, the service management is becoming more and more complicated, and the difficulty is also improved, which provides the help for the new crisis. The prevention and identification of the service crisis, largely dependent on the service staff and management of self-identification and assessment, the crisis control and processing effect embody the manager's ability and quality. This also highlights the importance of management in the prevention and disposal of service crises.

\subsection{The continuity and diversity of readers demand changes leads service crisis} prevention more difficult

Modern university readers are more active in trying and accepting new things. With the vision broad and the development of demand of the reader, the library's service capacity also has been put forward higher requirements, it also show a diversified, hierarchical development trend. For the library, we must fully address the objective needs of user changes, based on their own service resources to carry out innovation and to maximize the user's service capabilities. If the library want to obtain the user's recognition and support, avoid the occurrence of service crisis, it must make social development in sync from concept to behavior , in order to provide users with full of the information services.

\subsection{The quality of library services has become increasingly prominent; the quality of service crisis needs attention}

At present, in the management of university library service crisis, the problem of digital service evaluation system is generally manifested, which leads to the lack of objective judgment of the effect of the new service of the library, which leads to the lack of basis for improving the adjustment and the development and promotion of its own. If we can make micro blogging, We Chat and other new information media to play an important role, design and develop a new service quality scoring system, timely accept feedback information of users, give effective suggestions to users, we can improve the validity of the service. 


\section{Research on the Management Strategy of University Library Service Crisis} 4.1Eenhance the service crisis management philosophy, deepen the existing services item

In the face of the impact of the network library, the university library in reality must clearly understand its own development direction and service concept change mode, it should make the college student readers as the core, establish a deep level of service management ability, it cannot blindly exclude the modern electronic library, while it must ensure all the information carrier can re-sort, analyze the information of the student readers most concerned about, it will build a collection of professional services library as a development goal, and then make the field of information technology upgrades and software improvement as an opportunity to find an important theoretical basis for suitable development of university libraries .

Modern library changing the service concept needs to the current direction of technology development, especially the library institutions. The library institutions belong to the public welfare of the cultural industry, it should be in accordance with the upgrading of market technology, analyze college students readers preferences, establish a wide range of network e-library by different technologies Level, so that students can carry out the collection of project information, investigate research theory by their account ID authority. For some more professional problems, it can find other professional teachers by the library, to regularly hold lectures or exchange meetings to help students find a new way to build knowledge systems.

\subsection{Implementation of library service quality assessment}

The construction method of our library apply with the ARL library service evaluation model LibQuAL + TM which is currently available in the internationally recognized service quality assessment system. After years of international practice and summary, this system has been able to upgrade the library technology, play a scientific control and management, after the introduction of the library in China's construction; it brings a new strategic planning approach to achieve the quality of service quality of scientific progress.

With the improvement of information technology, the mobile services needs emerge in the society. The library service should be carried out with the different levels, according to the digital library assessment level and management methods to determine the effectiveness of the new quality assessment model, and then establish four dimensions of service evaluation which contain service environment, service interaction, and information control and service effects.

\subsection{Expand publicity; strengthen the reader information literacy education}

In the process of information dissemination, we should use different advertising positions to strengthen the quality of the campus culture education, for example, the admission notice, training data and the form of salon management, information can be published through the window position, promoting the new information publicity. Library actively promotes the construction of new resources, such as lectures, professional exchanges, preaching and so on can be classified according to the quality of information. Training different groups of readers, which is an important way of exchange the collection of resources. 
In order to reverse the service crisis faced by the modern university library, in addition to strengthening the reader's ability to retrieve information, but also in the new media environment, to improve the reader's ability to filter information, especially make a lot of quality education information integration, According to the classification of library readership and the different educational level to carry out the network information resources to push and retrieve software innovation

\subsection{Improve the reader decision-making mechanism.}

The library is a social public service organization, which not only needs to protect the reader's legitimate rights and interests in the museum, but also can use the most advanced ways and means to protect the reader's reading from other factors. Modern library can strengthen the link between the reader, but also make readers as the core of improving service capabilities and quality, it actively promote a wide range of readers exchange activities according the needs of readers and information feedback,

To adjust the decision-making methods of the library manage with the concept of modern service, making the library funding apply to the broadest readers services to ensure that the direction of service is correct and scientific.

\section{Acknowledgement}

This paper is one of the research results of "Research on the Crisis Management of University Library Based on User's Needs" (Project No. 2015SGM10), which is the South China University of Technology basic scientific research of special higher education management project in 2015.

\section{References}

[1] Feng Lu, Liu Shihui. "The chaos theory" point of view of the library crisis management new program [J]. Lan Taiwan World. 2015 (20): 87-88.

[2] Tang Yanqi. Library service crisis in information age and its solution strategy [J]. Chinese and foreign entrepreneurs. 2015 (09): 198-200.

[3] Wang Qi, Wang Kunqian, Du Yufang. Strategy of university library service crisis under network environment [J]. Information Science. 2013 (06): 83-88.

[4] Ma Xueliang, Fu Ping. Library Service Crisis Management in Digital Times Based on SWOT Analysis and Realization [J]. Library and Information Work. 2009, 53 (23): 22-25, 68. 